\title{
POSTOPERATIVE ANALGESIA FOLLOWING GESAREAN SECTION: INTRAVENOUS PARACETAMOL vs PETHIDINE
}

\author{
Shrestha A, Shrestha B
}

Department of Obstetrics and Gynecology, Nepal Medical College Teaching Hospital, Attarkhel, Gokarneshwor-8, Kathmandu, Nepal

\begin{abstract}
Effective analgesia is important after cesarean section. Intravenous paracetamol has been internationally accepted as a part of multimodal approach to pain management in post operative period. The purpose of the study was to compare the efficacy of intravenous paracetamol with pethidine in postoperative pain management in cesarean section. One hundred and eight patients undergoing cesarean section were studied over six months. The patients were divided into two equal groups. Group I received $900 \mathrm{mg} / 100 \mathrm{ml}$ of intravenous paracetamol at the end of surgery and every $6 \mathrm{hrs}$ for $24 \mathrm{hrs}$ and group II received intramuscular $50 \mathrm{mg}$ pethidine every 8 hours. Intramuscular Diclofenac sodium $75 \mathrm{mg}$ was used as a rescue drug to both the groups. Visual analogue score was used to assess the pain level at 6,12 and 24 hours postoperatively. The postoperative pain scores in both the groups were comparable. There was no significant difference in the consumption of additive analgesics. On the basis of current study we can reasonably recommend intravenous paracetamol in the postoperative pain management after cesarean section as it maintains a sustained and safe analgesic as it does not have side effects.
\end{abstract}

\section{KEYWORDS}

Cesarean section, paracetamol, pethidine, postoperative pain management, visual analogue score

\section{CORRESPONDING AUTHOR}

Dr. Astha Shrestha

Lecturer,

Department of Obstetrics and Gynecology,

Nepal Medical College and Teaching Hospital, Attarkhel, Gokarneshwor-8, Kathmandu, Nepal

Email: drasthashr57@gmail.com 


\section{INTRODUCTION}

Cesarean delivery is one of the most common surgical procedures performed in obstetrics worldwide. ${ }^{1}$ Surgery is the most common and predictable source of pain in the hospital setting and postoperative pain is the expected outcome for people who undergo surgery. The effective pain relief in the postoperative setting is a priority for patients and providers. ${ }^{1}$ Unrelieved pain after surgery is highly prevalent. ${ }^{2}$ It greatly impacts morbidity and mortality. It leads to an increase length of hospital stay and readmission rates, which contributes to higher healthcare costs. ${ }^{2}$ Effective pain control after surgery is important to prevent negative outcomes such as tachycardia, hypertension, myocardial ischemia, decrease in alveolar ventilation, immobility, deep vein thrombosis, and poor wound healing. ${ }^{3}$

Multimodal approach using combinations of various analgesic techniques and different classes of drugs has been recommended for the pain management after surgery. Opioids are very effective analgesics and a primary component of multimodal pain management approach in postsurgical settings. ${ }^{4}$ However, they are associated with many undesirable side effects such as sedation, nausea, vomiting, pruritus and constipation. ${ }^{5}$ They are secreted into the breast milk which leads to sedation and respiratory depression in newborn infants. ${ }^{5,6,7}$

Paracetamol being a non-opioid analgesics is devoid of the potential risks of opioids. ${ }^{7}$ It has an established record of safety, efficacy and tolerance in adults. ${ }^{8}$ It is the first line drug recommended by the World Health Organization (WHO) in analgesic ladder approach for pain management. ${ }^{8,9}$ The analgesic and antipyretic properties of paracetamol have been attributed to the inhibition of COX 3 is oenzyme within the brain and reduction in CNS prostaglandin E2 production. ${ }^{10}$ It alone or in combinations with other NSAIDs can be used to decrease the postoperative pain effectively. Its safety and tolerability profile is a greater advantage over other analgesics. In contrast to opioid, paracetamol does not produce sedation, respiratory depression, ileus and constipation, and is not associated with dependence or misuse..$^{1,6,7}$ Paracetamol is well tolerated drug but at times may cause nausea, vomiting, abdominal pain, diarrhea and rarely liver toxicity. ${ }^{6,7}$

The drug interaction of the paracetamol is less and has very few contraindications. Several studies have shown its potential benefit in postoperative pain relief. Hence, intravenous Paracetamol could be a new addition to the postoperative pain management with an advantage of decreased opioid consumption and its related side effects and decreased length of hospital stay with overall patient satisfaction. The purpose of this study was to compare the effectiveness of the intravenous paracetamol and pethidine in postoperative pain control in patient undergoing cesarean section in Nepal Medical College Teaching Hospital.

\section{MATERIALS AND METHODS}

The prospective cross sectional study was done after getting approval from the Institutional Review Committee of Nepal Medical College. After getting the written informed consent, 108 healthy parturient with ASA physical status I or II, scheduled to undergo caesarean section at Nepal Medical College Teaching Hospital were enrolled for the study over the period of six months from December 2016 to May 2017.

Patient with known contraindication to paracetamol or pethidine, history of severe allergy, hepatic, renal, cardiovascular and pulmonary disease, pre-eclampsia and Eclampsia were excluded from the study. Standard spinal anesthesia and surgical techniques were used. If spinal anesthesia failed, then General anesthesia was given and the patient was excluded from the study. Consecutive Patients were taken and divided into two equal groups. Group I received $900 \mathrm{mg}$ in $100 \mathrm{ml}$ of intravenous paracetamol at the end of surgery and every 6 hours for 24 hours and group II received intramuscular $50 \mathrm{mg}$ pethidine every 8 hours. Diclofenac sodium 75 mg was given intramuscularly as a rescue drug to both the groups. Visual analogue score (pain scale from 0 to 10,0 being the least and 10 being the worst pain) was used to assess the pain level at 6,12 and 24 hours postoperatively. The data was collected and recorded in a proforma. SPSS version 16.1 software was used to analyze the data. Student t test was used for analysis. $p$ value of $<0.05$ was considered significant.

\section{RESULTS}

There was no significant difference in patients' demography including the age of the patient, parity, gestational age at delivery or the number of prior cesarean deliveries between the two groups. (Table 1)

Table 1: Patient Characteristics and Obstetric Data

\begin{tabular}{lccc} 
Variables & Pethidine & Paracetamol & P value \\
$\begin{array}{l}\text { Age years } \\
\text { (Mean } \pm \text { SD) }\end{array}$ & $\begin{array}{c}28.78 \pm \\
3.79\end{array}$ & $29.6 \pm 3.24$ & $<0.05$ \\
$\begin{array}{l}\text { Gestational } \\
\begin{array}{l}\text { Age (days) } \\
\text { (mean } \pm \text { SD) }\end{array}\end{array}$ & $\begin{array}{c}270.57 \pm \\
5.43\end{array}$ & $271.67 \pm 5.76$ & $<0.05$ \\
$\begin{array}{l}\text { Repeat } \\
\text { cesarean } \\
\text { section(n) \% }\end{array}$ & $8(14.8)$ & $9(16.6)$ & $<0.05$ \\
$\begin{array}{l}\text { Primipara } \\
\text { (n) \% }\end{array}$ & $32(59.2)$ & $33(61.1)$ & $<0.05$ \\
$\begin{array}{l}\text { Multipara } \\
\text { (n) \% }\end{array}$ & 14(25.9) & $12(22.2)$ & $<0.05$ \\
\hline
\end{tabular}


The pain score was maximum at the 6 hours in the paracetamol group was 1.85 and the mean visual analogue score was 2.02 in the pethidine group which is more than the paracetamol although the difference was not statistically significant. The decrease in the pain score was more in the paracetamol group as compared to the pethidine group though the difference was not statistically significant (Table 2).

\begin{tabular}{|lllll|}
\hline Table 2: Mean Visual Analogue Score \\
\hline Time in hrs & 0 hrs & 6 hrs & $12 \mathrm{hrs}$ & $24 \mathrm{hrs}$ \\
Paracetamol & 1.07 & 1.85 & 0.96 & 0.27 \\
Pethidine & 1.17 & 2.02 & 1.07 & 0.29 \\
p - value & 0.52 & 0.44 & 0.49 & 0.35 \\
\hline
\end{tabular}

Only 10 patients out of 54 required rescue analgesics in the paracetamol group whereas 20 out of 54 required rescue analgesic in case of pethidine group. However, the difference was not statistically significant (Fig. 1).

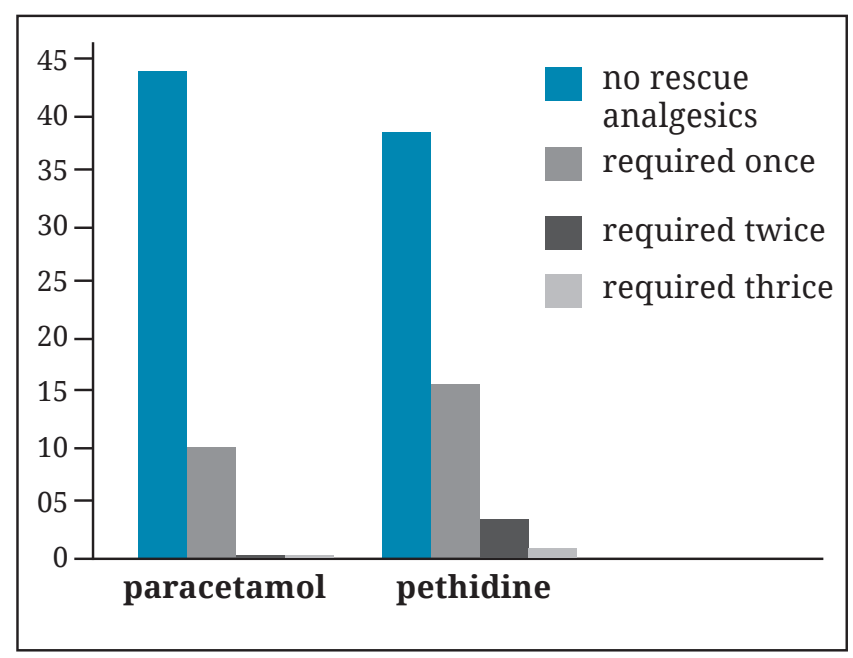

Fig. 1: Patient requiring rescue analgesics.

The side effect was not observed in the paracetamol or the pethidine group.

\section{DISCUSSION}

The International Association for the Study of Pain defined pain as "an unpleasant sensory and emotional experience associated with actual or potential tissue damage or described in terms of tissue damage". ${ }^{11}$ Pain has been classified as nociceptive, inflammatory, and pathological based on its neurobiological perspective. ${ }^{12}$ Pain is a predictable experience after surgery due to tissue and nerve injury caused by the surgical procedure. Cesarean section constitutes a public health priority as it is one of the common major surgeries in the obstetrical practice. The rate of cesarean delivery is increasing every year. There is a concern for maternal health relating to this type of delivery. The pregnant mothers who opt for cesarean section are not that much scared of surgery as such but about pain which follows it. ${ }^{1}$

Women who are undergoing cesarean section want to be free to attend their babies and do not like to be sleepy, drowsy or restricted by the equipments. ${ }^{6}$ Proper pain control is essential not only in intraoperative period but also in the immediate postoperative period. ${ }^{6}$ Effective management of postoperative pain is a priority for patients and service providers; the goal is to relive pain while keeping side effects to minimum. ${ }^{2}$

Extended periods of unrelieved acute pain can result in physiologic changes that include pituitary-adrenal activation. This results in diminished immune response that interferes in wound healing and sympathetic activation. In addition, unrelieved postoperative pain causes the avoidance of movement with delayed surgical recovery and this inability may contribute to longer hospital stays and read missions after discharge. ${ }^{2}$

Persistent post operative pain even after healing of the surgical lesion is prevalent which is now been recognized as an important clinical and perhaps social problem..$^{13}$ Effective postoperative pain management is important and necessary for improving quality of life and minimizing patient morbidity. ${ }^{14}$ Healthcare providers can facilitate better pain control after surgery by implementing and applying evidence-based analgesic practices. The ultimate goal of postoperative pain management is choosing an effective, safe drug regimen with minimal adverse effects and maximum pain relief for better patient outcomes. ${ }^{15}$

Multimodal analgesic approach was introduced and is been in the practice. ${ }^{16}$ It involves the use of the multiple agents acting in the different regions of the pain pathway. The rationale behind this approach is that it reduces the use of opioids and its side effects. ${ }^{16}$ The advantage of using intravenous paracetamol is that it is safe, can be used alone or in conjunction with other drugs and has few clinically significant side effects. ${ }^{16}$

In our study, we used intravenous paracetamol for postoperative pain management and compared it with pethidine. We assessed pain score at 0,6 , 12 and 24 hours. The pain score was comparable in both the groups. Only 10 out of 54 patients required the rescue analgesics where as 20 out of 50 patient required rescue analgesics in the pethidine group. Although this study does not directly demonstrate the efficacy of paracetamol over pethidine, but we could see that the paracetamol has better analgesic property. The pain was maximum at 6 hrs post operative and gradually decreased in both groups but the score was lesser in paracetamol group as compared to pethidine group.

One of the meta-analysis concluded that a single dose of intravenous paracetamol is a valuable 
medication to help diminish the postoperative pain. ${ }^{17}$ In our study as well, we found that intravenous paracetamol can effectively reduce the postoperative pain. ${ }^{17}$ Sinatra et $a l^{18}$ in the year 2005 conducted a randomized, double-blind, placebo-controlled multi dose study in seven US centers to evaluate the analgesic efficacy and safety of intravenous paracetamol compared with its prodrug (Propacetamol) and placebo. Based on the study results, the authors concluded that intravenous paracetamol(1gram) administered over a 24-hour period in patients with moderate to severe pain after major orthopedic surgery provided rapid and effective analgesia and was well tolerated. In our study, paracetamol was well tolerated and provided good analgesia as well.

Macario and Royal, ${ }^{19}$ performed a literature review of randomized clinical trials of intravenous paracetamol for acute postoperative pain management to assess the analgesic outcomes of it. Of these participants, 780 patients received intravenous paracetamol $(n=1464)$. Seven out of eight comparator studies showed intravenous paracetamol had similar analgesic outcomes as the comparator. They concluded that intravenous paracetamol is an effective analgesic across a variety of surgical procedures. which is similar to that found in our study.

Wininger et $a l,{ }^{20}$ conducted a randomized, double-blind, placebo-controlled, parallelgroup study to evaluate the analgesic efficacy and safety of repeated doses of two regimens of intravenous acetaminophen (paracetamol) compared with placebo over 24 hours in subjects with moderate to severe pain after abdominal laparoscopic surgery. This study concluded that both intravenous paracetamol regimens (1gram every six hours and 650 milligrams every four hours) were associated with significant pain relief compared with placebo and were well tolerated in abdominal laparoscopic surgical patients. In our study as well the analgesic efficacy was comparable and well tolerated.

Memis et $a l^{21}$ in the year 2010 conducted a study in patients undergoing major abdominal orpelvic surgery. The authors aimed to assess analgesic efficacy, adverse effects of intravenous paracetamol after major surgery. They suggested that intravenous paracetamol is useful component of the multimodal analgesia model, especially after major surgery; which is similar to our study.

A study done in 2006 by Inal et $a l^{22}$ included 50 ASA I \& II patients who were planned for cesarean delivery. The patients were randomly allocated either to receive intravenous paracetamol $1 \mathrm{gm}$ or intravenous pethidine $100 \mathrm{mg}$ and VAS score were recorded. They observed that VAS score in pethidine group were higher than in the paracetamol group. This is in consistent with the result obtained in our study.
A prospective randomized study was conducted over a period of 6 months in the year 2015 with 144 patients undergoing cesarean section. They were randomly divided into the paracetamol suppository group and the pethidine group. Mean visual pain score were analyzed. They observed a higher satisfaction score in the paracetamol group and also there was less consumption of the rescue analgesia $(p<0.001)$. They concluded that the analgesic regimen with paracetamol has not only enhanced patient satisfaction but also reduced opioid consumption thus reduced intramuscular frequency of injection in the postoperative ward. ${ }^{23}$ In our study the mean visual analogue score is less in the paracetamol group as with less requirement of the rescue analgesics. A prospective randomized double blind clinical trial was conducted in 2014 in 100 ASA I \&II parturient scheduled for elective cesarean section under spinal anesthesia. Patient either received $1 \mathrm{gm}$ paracetamol or the normal saline only. They found low pain score in the paracetamol group $(p<0.0001)$. Hence they concluded that the intravenous paracetamol reduces the intensity of pain and overall opioid consumption. ${ }^{7}$ In our study, the mean visual analogue score was less in the intravenous paracetamol group as compared to the pethidine group. Analysis of the evidence revealed that intravenous paracetamol is effective in reducing cesarean delivery postoperative pain. One study showed a statistically significant reduction $(\mathrm{p}<0.05)$ in visual analogue score at 4 and 24 hours postoperatively. The result is also in agreement with the our study. ${ }^{22}$

Munishankar et $a l^{24}$ conducted a double blind randomized controlled trial in 2008 using the paracetamol, diclofenac or their combination and pethidine as a rescue analgesic in patients undergoing cesarean section. They observed 38\% less use of the opioid analgesic inpatient who received the combination drug. In our study, the rescue analgesic consumption was less in the paracetamol group than in the pethidine group. Our study revealed that the patient who received the intravenous paracetamol required the rescue analgesic after a longer period as compared to the pethidine group. These findings are reinforced in another prospective randomized trial by Atashkhoyi, ${ }^{7}$ with findings showing an increased time to first analgesic and decreased time to ambulation and decreased cumulative postoperative analgesic consumption in the patient receiving intravenous paracetamol.

Idenhen et $a l^{25}$ had conducted a comparative study with diclofenac and intravenous Paracetamol combination vs the intramuscular pethidine in post cesarean section in the year 2015. The study demonstrated that the combination of paracetamol infusion and diclofenac has similar analgesic efficacy as the pethidine. They concluded that it can be used as an effective substitute for the pethidine. In our study the paracetamol had an equal analgesic efficacy as the pethidine hence 
paracetamol could be used as a post operative analgesic.

The prospective double blinded randomized trial by Omar and Alissa, ${ }^{6}$ showed no rescue drug required in the intravenous paracetamol group as compared to the $25 \%$ of the control group required multiple doses of the rescue analgesic for the pain control, ${ }^{7}$ which is similar to that we observed in our study.

Another study has also shown that the intravenous paracetamol provides good quality postoperative analgesia with decreased consumption of morphine and no side effects after total abdominal hysterectomy. ${ }^{26}$ The result from this study is consistent with the study in which intravenous paracetamol is an effective analgesic in treatment of the postoperative acute pain after abdominal laparoscopic procedure with a good safety profile. ${ }^{19}$

In a quantitative report, Groudine and Fossum, ${ }^{27}$ had analyzed regarding the safety and efficacy of intravenous paracetamol, they found that intravenous paracetamol could be a reasonable component of non-opioid analgesics with less side effects. In our study there were no side effects noted in both the groups. Intravenous paracetamol does not have the side effects like the respiratory depression, sedation as that of the opioids like pethidine and at the same time it is a good analgesic to decrease the postoperative pain. In this study, intravenous paracetamol is used as the postoperative analgesic and we found that it gave adequate pain relief with significantly less use of the rescue analgesic drug. In the pethidine group, ${ }^{20}$ out of the 54-patient required the rescue analgesic whereas only 10 patients in the paracetamol group required the rescue analgesic.

Intravenous paracetamol maintains a sustained and effective analgesia in the postoperative period following cesarean section. Hence we can conclude that the intravenous paracetamol can be used as analgesics in the postoperative period of cesarean section.

\section{REFERENCES}

1. Olivera, Januario MBM, Quental LLP et al. Acetaminophen and the Pain Management in Cesarean Post- Operatory. Int'l Archieves Med 2015; 8: $1-6$.

2. Hutchison R.W. Challenges in acute post-operative pain management. Am J Health-Syst Pharm 2007; 64: S2-5.

3. Vadivelu N, Mitra S, Narayan D. Recent advances in postoperative pain management. Yale J Biol Med 2010; $83: 11-25$.

4. Veerabhadram G, Christina C. Postoperative pain control. Clini Colon Rectal Surg 2013; 26: 191-6.

5. White PF. Multimodal pain management the future is now! Curr Opin Investig Drugs 2007; 8: 517-8.

6. Abu Omar AA, Alissa KA. Intravenous paracetamol(Prefalgan) for analgesia after cesarean section: A double blind randomised controlled study. Rawal Med J 2011; 36: 1- 12.

7. Atashkhoyi S, Rasouli S, Fardiazar Z, Ghojazadeh M, Marandi PH. Preventive Analgesia with intravenous paracetamol for post cesarean section pain control. Int'l J Women's Health Repro Services 2014; 2: 131-7.

8. Duggan, S \& Scott, L. Intravenous Paracetamol Adis Data Information 2009.

9. GrisellVagas- Schaffer. Is the WHO analgesic ladder still valid? Can Fam Physician 2010; 56: 514-7.

10. Regina $\mathrm{M}$ Botting.Mechanism of Action of Acetaminophen. Is there a Cyclooxygenase 3? Clin Infec Dis 2000; 31: S 202 - 10.

11. International Association for the Study of Pain. 2011

12. Woolf, C. What is this thing called pain? J Clin Invest 2010; 120:11.
13. Yarnitsky D, Crispel Y, Eisenberg E et al. Prediction of chronic post operative pain: Pre-operative DNIC testing identifies patients at risk. Pain 2008; 138:22-8.

14. Cregg R, Anwar S, Farquhar-Smith P. Persistent postsurgical pain. Curr Opin Support Palliat Care 2013; 16: 144-152

15. Smith, H. S. Perioperative Intravenous Acetaminophen and NSAIDs. Pain Medicine 2011; 12: 961-81.

16. Elvir-Lazo O, White PF. The role of multimodal analgesia in pain management after ambulatory surgery. Curr Opinion Anesthesiol 2010; 6: 697-703.

17. De Olivera GS, Castro-Alves LJ \& McCarthy RJ. Single dose systemic acetaminophen to prevent postoperative pain: a metaanalysis of randomized control trails. Clin J Pain 2015; 31: 86- 93.

18. Sinatra RS, Jahr JS, Reynolds LW, Viscusi ER, Groudine SB, Payen-Champenois C. Efficacy and safety of single and repeated administration of 1 gram intravenous acetaminophen injection (paracetamol) for pain management after major orthopedic surgery. Anesthesiol 2005; 4: 822-31.

19. Macario A, Royal MAA. Literature review of randomized clinical trials of intravenous acetaminophen (paracetamol) for acute postoperative pain. Pain Practice 2010; 11.

20. Wininger SJ, Miller H, Minkowitz H et al. Repeat-Dose Study of Two Intravenous Acetaminophen Dosing Regimens for the Treatment of Pain after Abdominal Laparoscopic Surgery. Clin Therapeutics 2010; 32: 2348-69.

21. Memis, D., Inal, M.T., Kavalci, G, et al. Intravenous paracetamol reduced theuse of opioids, extubation time, and opioid-related adverse effects after majorsurgery in intensive care unit. J Critical Care 
2010; 25: 458-62.

22. M Inal, Celk F Tuncay. IV Paracetamol Infusion Is Better than IV Mepherdine Infusion for Postoperative Analgesia After Caesarean Section. The Int'l J Anests 2006; 16: 12-4

23. M Hasan, Haque M, Islam R, Ferdousi MA, WahabMA. Non-opioid rectal suppositorues in post cesarean delivery pain management - a randomised trial. J Soci Anesthes Nepal 2015; 2:56 - 61.

24. Munishankar B, Fettes P, Moore C, McLeod GA. A double - blind randomised controlled trial of paracetamol, diclofenac or the combination for pain relief after cesarean section. Intern J Obs Anesth 2008; 17: 9 -14
25. Idehen HO, Edowmonyi NP, Imarengiaye CA, Kute MO. A comparative Study of Combination of Paracetamol Infusion (Perfalgan) and Intramuscular Diclofenac versus Intravenous pethidine, in the Management of Post Caesarean Pain. Nigerian Postgrad Med J 2015; 22: $50-5$.

26. Moon Y, Lee Y, Lee J, Moon D. The effects of preoperative intravenous acetaminophen in patient undergoing abdominal hysterectomy. General Gynecol 2011; 284: 1455-60.

27. Groudine S, Fossum S. Use of intravenous acetaminophen in the treatment of postoperative pain. J Peri Anesth Nurs 2011; 26: $74-80$. 